\section{Outcome measures in chronic obstructive pulmonary disease (COPD)} A Dirksen

\section{Lung density determined by $\mathrm{CT}$ scanning may be a useful outcome measure in COPD}

$\mathrm{F}$ orced expiratory volume in 1 second $\left(\mathrm{FEV}_{1}\right)$ is by far the most well established outcome variable in obstructive pulmonary disease. Numerous studies have documented the correlation of this parameter with clinical variables such as severity of disease and mortality, ${ }^{1}$ and spirometric measurements have been standardised by international recommendations on lung function testing. ${ }^{2}$ Nevertheless, in real life the relevance of a maximal blow through a narrow tube is not always self-evident, and the intuitive clinical meaningfulness of this surrogate parameter is therefore perhaps less obvious. $\mathrm{FEV}_{1}$ has further limitations in chronic obstructive pulmonary disease (COPD). In general, dynamic lung volumes such as $\mathrm{FEV}_{1}$ and forced vital capacity (FVC) are highly effort dependent. However, in emphysematous subjects an abnormally low $\mathrm{FEV}_{1}$ is partly caused by the dynamic collapse of the airways which is also effort dependent. Therefore, in COPD the result of a more moderated manoeuvre is usually superior to the result of a maximal effort. This phenomenon adds to the variability of repeated measurements and, in COPD, the standard deviation of repeated measurements of $\mathrm{FEV}_{1}$ is larger than the annual decline, even in heavy smokers. ${ }^{3}$ For these reasons there is an increasing interest in other measures such as number of exacerbations or disease specific questionnaire scores as alternative outcome measures for monitoring the progress of emphysema in randomised clinical trials.

Another new outcome measure is lung density as determined by computed tomographic (CT) scanning. Although the scanner has mainly been used as an imaging device, in the 1970s when Hounsfield developed CT scanning for clinical use he envisaged the scanner as a measuring device as well, because it provides precise information on the density of tissues derived from the attenuation of $x$ rays. In this context it should be noted that pulmonary emphysema is defined pathologically as "the abnormal permanent enlargement of airspaces distal to the terminal bronchioles due to destruction of their walls, without obvious fibrosis". ${ }^{4}$ In other words, loss of lung tissue is an essential and inevitable part of the emphysematous process, and no other reasonably common and diffuse lung disease shares this feature with emphysema. CT based densitometric parameters therefore have the potential to be both sensitive and specific outcome measures for monitoring the progress of emphysema.

Even in the late 1970s and early 1980s emphysema was described by CT scanning. ${ }^{56}$ Since that time, several studies have compared CT and pathological findings and-with improved resolution, faster scan times, and thinner collimation-the correlation between CT scores and pathological grading has improved. Furthermore, recent studies seem to indicate that CT lung density is more reproducible than traditional spirometric variables such as $\mathrm{FEV}_{1}{ }^{7}$

Two papers in this issue of Thorax add important data to the validation of CT lung density as an outcome measure for monitoring the progress of emphysema. In both studies participants suffered from severe $\alpha_{1}$-antitrypsin (AAT) deficiency (assumed $\mathrm{PI}$ ZZZ genotype) and both studies included St George's Respiratory Questionnaire (SGRQ) data, lung function tests $\left(\mathrm{FEV}_{1}\right.$ and transfer coefficient (KCO)), and CT lung density measurements. Dawkins et al $^{8}$ followed about 200 subjects for a mean of 2 years. Twenty subjects who died after enrolment in the study had lower FEV (percentage predicted), Kco (percentage predicted), higher CT emphysema index (threshold -910 HU), and higher SGRQ scores indicating worse health status than survivors. Subsequent multiple regression analysis (Cox survival) showed that the CT emphysema index was the most powerful predictor of mortality followed by the SGRQ activity score, whereas age and lung function measurements had no independent influence on survival. In the study by Stolk et $a l^{9} 22$ individuals were followed for 30 months and a significant correlation was found between changes in CT lung density (percentile density) and changes in health status (SGRQ) but, surprisingly, no correlation was seen between these variables and changes in pulmonary function measurements $\left(\mathrm{FEV}_{1}\right.$ and KCO).

Patients with severe AAT deficiency provide a good model for studies of emphysema because they develop the disease at a relatively young age when health status is less affected by comorbidities that become more prevalent with increasing age. However, these studies do also have limitations. Although 200 subjects is a large group for studies of AAT deficiency, it is a more moderate number compared with other studies in usual COPD and the results obtained in AAT deficiency may not necessarily be applicable to the much larger population of smokers with usual COPD.

From a methodological point of view, it is interesting to note the difference between the two studies in the selection of the CT densitometric parameter and CT protocol for image acquisition. Thus, Dawkins et al used the emphysema index and an HRCT protocol (that is, thin slices and a hard reconstruction) whereas Stolk et al chose the percentile density and a volume scan protocol (that is, thick slices and a soft reconstruction algorithm). Owing to photon statistics, thick collimation and soft reconstruction usually give more reliable results and the percentile density seems to be more robust than the emphysema index, at least in longitudinal studies of the progress of emphysema. ${ }^{10}$

The radiation burden is always an important consideration when using $x$ rays for monitoring disease, and the radiation dose of a standard CT scan of the chest is by no means negligible. However, by reducing the current of the $x$ ray tube, it is possible to keep the total radiation dose of a full volume scan of the lung below $1 \mathrm{mSv}$ without significant loss of information on lung density. This low dose technique opens up the possibility for longitudinal studies with repeated CT scans in the same subject. Volume scanning has two important advantages: (1) using modern multislice techniques the scan can be performed in one breath hold, and (2) the amount of air in the lungs can be calculated from the images. Lung density is obviously very dependent on inspiratory level, and the volume of air in the lungs can be used to adjust lung density for the inspiratory level. ${ }^{10}$ When analysing trends in longitudinal data such as in the study by Stolk et al, adjustment for lung volume is unavoidable because the total lung volume of a subject may vary significantly from one 
examination to the next. ${ }^{10}$ This kind of noise reduction may be less important in cross sectional studies such as the one by Dawkins et $a l^{8}$ and it may even introduce new errors. An increase in total lung volume is an inherent part of the emphysematous process and, by eliminating that aspect of the disease, volume adjustment may in fact weaken the correlation between CT lung density and other measures of disease severity (unpublished data). Thus, adjustment of lung density for lung volume is not always to be recommended.

The two studies published in this issue of Thorax underline the urgent need for standardisation and international agreement on recommendations for lung density measurement based on CT scanning. However, provided CT lung density can be standardised and validated against traditional clinical outcome variables, it may prove to be a new measurement that is objective, specific, and sensitive for monitoring the effect of new drugs on the progress of emphysema in future randomised clinical trials.

\section{Thorax 2003;58:1007-1008}

\section{Author's affiliation}

A Dirksen, Department of Respiratory

Medicine, Gentofte University Hospital, DK-

2900 Hellerup, Denmark; adi@dadlnet.dk

\section{REFERENCES}

1 Lange P, Nyboe J, Appleyard M, et al. Spirometric findings and mortality in neversmokers. J Clin Epidemiol 1990;43:867-73.

2 Quanjer PH, Tammeling GJ, Cotes JE, et al. Lung volumes and forced ventilatory flows. Report Working Party Standardization of Lung Function Tests, European Community for Steel and Coal. Tests, European Community for Steel and Coal.
Official Statement of the European Respiratory Society. Eur Respir J Suppl 1993;16:5-40.

3 Dirksen A, Holstein-Rathlou NH, Madsen F, et al. Long-range correlations of serial FEV measurements in emphysematous patients and normal subjects. J Appl Physiol 1998;85:259-65.

4 National Heart, Lung, and Blood Institute. The definition of emphysema. Report of a National Heart, Lung, and Blood Institute, Division of Lung Diseases workshop. Am Rev Respir Dis 1985; 132:182-5.

5 Goddard PR, Nicholson EM, Laszlo G, et al. Computed tomography in pulmonary emphysema. Clin Radiol 1982;33:379-87.

6 Rosenblum LJ, Mauceri RA, Wellenstein DE, et al. Computed tomography of the lung. Radiology 1978;129:521-4.

7 Dirksen A, Dijkman JH, Madsen F, et al. A randomized clinical trial of alpha -antitrypsin $_{1}$ augmentation therapy. Am J Respir Crit Care Med 1999; 160:1468-72.

8 Dawkins PA, Dowson $\sqcup$, Guest PJ, et al. Predictors of mortality in $\alpha_{1}$-antitrypsin deficiency. Thorax 2003;58:1020-6.

9 Stolk J, Ng WH, Bakker ME, et al. Correlation between annual change in health status and computer tomography derived lung density in subjects with $\alpha_{1}$-antitrypsin deficiency. Thorax 2003;58:1027-30

10 Dirksen A, Friis $M$, Olesen KP, et al. Progress of emphysema in severe $\alpha_{1}$-antitrypsin deficiency as assessed by annual CT. Acta Radiol

1997;38:826-32

\section{Asthma and obesity: where are we now? \\ S Chinn}

\section{The importance of the reported association between obesity and asthma is still unclear}

A $\mathrm{n}$ association between asthma and overweight or obesity was first reported in adults in the 1980s. ${ }^{12}$ The papers were concerned with chronic disease in general and excited little attention in the respiratory field at the time. In children concern had been over growth retardation in those with asthma. ${ }^{3}$ In 1984 Somerville et $a l^{4}$ reported a weak association between symptoms of asthma and increasing weight for height, but again this provoked little interest.

In the last 5 years there have been numerous reports of an association in adults and in children-too many to cite directly. ${ }^{5}$ Even since the later of these two reviews there have been further reports in children, ${ }^{7}$ in adults, ${ }^{8}$ and specifically in women. ${ }^{9}$ The lack of earlier reports does not necessarily imply that the association is recent because, when the prevalence of obesity was lower, there was less power to detect a raised prevalence or incidence in obese subjects. However, in addition to this indirect evidence, there is some direct evidence for the association being recent in origin. In a study of children aged 5-11 years in Britain carried out over 23 years, in contrast to the weak association in the 1977 data cited above, a strong association was found in data collected in 1994. ${ }^{10}$ In adults there is evidence for an association between asthma and obesity in Britain as early as 1982, but no other reports to show whether the relation existed earlier. ${ }^{6}$ Obesity, defined as a body mass index (BMI) of 30 or more, had already reached $14 \%$ in adults in the US by the early 1970s, ${ }^{11}$ a figure comparable to that reached in England in 1993, ${ }^{12}$ so it seems likely that the association, if present, could have been detected in

\section{THE EVIDENCE Confounding}

Studies in adults have found associations between reported asthma or the US earlier than the 1980s. symptoms (rather than doctor diagnosed asthma) and BMI and, in a few studies, height and weight were also self-reported. This has led to some scepticism that the association is spurious or due to confounding ${ }^{13}$ or, at most, the result of increased perception of symptoms among those who are overweight. ${ }^{14}$ Schachter et al found an association between symptoms and medication for asthma and increasing BMI, but not airway responsiveness (AHR), in 1971 adults aged 17-73 years, ${ }^{14}$ and in this issue of Thorax they present similar findings in 5993 children aged $7-12$ years. $^{15}$

The association is not simply due to concomitant trends in asthma and obesity, as suggested by Wilson. ${ }^{13}$ The association is not ecological but is found in individual data and, while in the UK the trends in BMI and asthma have been concurrent in children, the trend in BMI does not explain the trend in asthma due to the recent nature of the association. ${ }^{10}$ Wilson's alternative explanation was that it was due to confounding. Confounding can never be completely ruled out in observational studies, but the factors suggested by Wilson-gastro-oesophageal reflux and obstructive sleep apnoea-are not potential confounders but intervening variables on putative causal pathways. ${ }^{13}$

\section{Increased perception}

That the association may be due to increased perception of symptoms in obese individuals is much more difficult to rule out. Indeed, it can be assumed 
that part of the association is due to perception as lung function decreases with increasing BMI within individuals, ${ }^{16} 17$ although in cross sectional data an increase in lung function may be seen at lower BMI and a decrease only at higher values. ${ }^{18}$ The question is whether the association is entirely due to increased perception. The conclusions of Schachter et al were based on finding no trend of increasing AHR with greater BMI. ${ }^{14}{ }^{15}$ However, in 11277 participants in the European Community Respiratory Health Survey (ECRHS) a statistically significant trend was found even after adjusting for lung function, ${ }^{19}$ and a case-control study of men in the Normative Aging Study found a Ushaped relation with greater AHR at high and low BMI, also adjusted for lung function. ${ }^{20}$

There is other evidence for not dismissing the association as being entirely due to increased perception. In children, case-control studies comparing those with diagnosed asthma and those without showed that the asthmatic children had greater mean BMI. ${ }^{21} 22$ Furthermore, at least six longitudinal studies have shown an increased incidence of asthma in overweight or obese children and adults. $^{67} \mathrm{~A}$ delayed effect is more difficult to explain away than an immediate one by increased perception. In these studies incidence was calculated in those disease or symptom free at baseline. The lack of an agreed definition of asthma, and the difficulty of differentiating true incident asthma from recurrence of quiescent asthma, have provoked criticism of this approach. $^{23}$ However, the studies do make the reverse causation hypothesis-that lack of exercise in asthmatic patients promotes obesity-an unlikely explanation. These studies also provide evidence against the mechanical effects of obesity being the sole explanation, by the same argument as against increased perception and against a combination of perception and mechanical effects alone.

Studies of change in symptoms in obese asthmatic patients who lose weight have the potential to overcome the above scepticism. The one randomised controlled trial of 38 obese patients showed a reduction in symptoms and improvement in health status in the treated group compared with the control group, and an increase in lung function. ${ }^{24}$ However, at high BMI a reduction in weight is likely to increase lung function irrespective of symptoms, ${ }^{16}{ }^{17}$ so this may not have convinced the sceptics. Airway responsiveness was not measured. A large trial including AHR as an outcome could provide evidence that the change in reported symptoms is not entirely due to reduced perception with weight loss, although on its own it cannot determine whether obesity is a cause of asthma.

\section{Dietary factors}

Review articles have considered many possible explanations apart from confounding, mechanical effects, and perception. $^{56}$ Obesity may modify the immune system, female sex hormones may play a role, physical inactivity may independently promote obesity and asthma, and a large number of dietary factors may be implicated. ${ }^{5}$ In the randomised controlled trial weight reduction was achieved through a diet which was modified in content as well as in calories, ${ }^{24}$ and surgical reduction may lead to dietary changes. It may be feasible to collect dietary data in asthmatic patients motivated to lose weight, but a large study will be required to disentangle the candidate explanatory factors.

\section{Sex differences}

A number of studies have found an association between the prevalence or incidence of asthma in women but not in men, prompting a discussion of the mechanisms involving female sex hormones. However, the finding was not universal and, in the ECRHS, the association between AHR and obesity was, if anything, greater in men, ${ }^{18}$ but associations between symptoms and obesity were almost identical in men and women. ${ }^{25}$ Part of the explanation for this heterogeneity in the findings may be in study size and methodology. In order to conclude a different effect in men and women, a statistically significant interaction is required. It is not sufficient to observe a statistically significant relation in one group and not in the other, but studies may lack the power to detect an interaction. ${ }^{26} \mathrm{~A}$ number of studies have not reported a test of interaction but analysed data for men and women separately on a priori grounds because of the previous reports of differing associations. Others have reported a combined effect, so the evaluation of the evidence for and against a sex difference is quite difficult. In addition, some of the larger studies of adults showing a greater association in women analysed reported height and weight ${ }^{27}{ }^{28}$ which may have different validity in men and women. Only a large study with the power to detect an interaction effect can answer the question, but the interaction may genuinely differ between studies if the association is due to multiple mechanisms with difference contributions in different places.
Schachter et al found an association between BMI and atopy in girls, ${ }^{15}$ while Jarvis et al found no association with atopy in men or women, and no interaction between BMI and atopy on symptoms. ${ }^{25}$ Huang et al found an association between high BMI and both atopy and AHR in girls but not boys in Taiwan, ${ }^{29}$ the association with atopy explaining that with AHR. An association between BMI and atopy was reported in a study in Finland but no symptom data were included. ${ }^{30}$

\section{WHERE ARE WE NOW?}

The scientific community is divided over the importance of the reported association between obesity and asthma, over whether the association is confined to women and girls or not, and whether atopy is also associated and perhaps on a causal pathway. In addition, there are a number of plausible mechanisms with little or no evidence for or against their role. Only large studies which include AHR as an outcome are likely to add further to the debate. However, we can surely all endorse the plea made by Redd and Mokdad ${ }^{23}$ not to delay intervention programmes to tackle the obesity epidemic while we argue over the mechanisms for an association with asthma.

\section{Thorax 2003:58:1008-1010}

\section{Author's affiliation}

S Chinn, Department of Public Health Sciences, King's College London, 5th Floor, Capital House, London SEI 3QD, UK; sue.chinn@kcl.ac.uk

\section{REFERENCES}

1 Seidell JC, de Groot LCPGM, van Sonsbeek JLA, et al. Associations of moderate and severe overweight with self-reported illness and medical care in Dutch adults. Am J Public Health care in Dutch ad

2 Negri E, Pagano R, Decarli A, et al. Body weight and the prevalence of chronic disease. J Epidemio Community Health 1988;42:24-9.

3 Kaplan BA, Brush G, Mascie-Taylor CGN. The relationship of childhood asthma and wheezy bronchitis with height, weight and body mass index. Hum Biol 1987;59:921-31.

4 Somerville SM. Rona RJ, Chinn S. Obesity and respiratory symptoms in primary school. Arch Dis Child 1984:59:940-4

5 Tantsira KG, Weiss ST. Complex interactions in complex traits; obesity and asthma. Thorax 2001;56(Suppl II):ii64-ii74.

6 Chinn S. Obesity and asthma: evidence for and against a causal relation. J Asthma 2003:40:1-16.

7 Gilliland FD, Berhane K, Islam T, et al. Obesity and the risk of newly diagnosed asthma in schoolage children. Am J Epidemiol 2003:158:406-15.

8 Mokdad AH, Ford ES, Bowman BA, et al. Prevalence of obesity, diabetes, and obesityrelated health risk factors, 2001. JAMA 2003:289:76-9

9 Romieu I, Avenel V, Leynaert B, et al. Body mass index, change in body silhouette, and risk of 
asthma in the E3N cohort study. Am J Epidemio 2003; 158:165-74.

10 Chinn S, Rona RJ. Can the increase in body mass index explain the rising trend in asthma in children? Thorax 2001;56:845-50.

11 Flegal KM, Carroll MD, Kuczmarski RJ, et al. Overweight and obesity in the United States: prevalence and trends, 1960-1994. Int J Obesity Relat Metab Disord 1998:22:39-47.

12 Bennett N, Dodd T, Flatley J, et al. Health Survey for England 1993. London: HMSO 1995:39.

13 Wilson MM. The association of asthma and obesity. Is it real or a matter of definition. Presbyterian ministers' salaries and earlobe creases? Arch Intern Med 1999;159:2513-4.

14 Schachter LM, Salome CM, Peat JK, et al. Obesity is a risk factor for asthma and wheeze but not for airway hyperresponsiveness. Thorax 2001;56:4-8

15 Schachter LM, Peat JK, Salome CM. Asthma and atopy in overweight children. Thorax 2003;58:1031-5.

16 Carey IM, Cook DG, Strachan DP. The effects of adiposity and weight change on forced expiratory volume decline in a longitudinal study of adults. Int J Obes Relat Metab Disord 1999;23:979-85.
17 Bottai M, Pistelli F, Di Pede F, et al. Longitudinal changes of body mass index, spirometry and diffusion in a general population. Eur Respir J 2002:20:665-73.

18 Pisteli F, Bottai M, Viegi G, et al. Smooth reference equations for slow vital capacity and flow-volume curve indexes. Am J Respir Crit Care Med 2000;161:899-905.

19 Chinn S, Jarvis D, Burney P. The relation of bronchial responsiveness to body mass index in the ECRHS. Thorax 2002; 57:1028-33.

20 Litonjua AA, Sparrow D, Celedon JC, et al. Association of body mass index with the development of methacholine airway hyperresponsiveness in men: the Normative Aging Study. Thorax 2002;57:581-5.

21 Luder E, Melnik TA, DiMaio M. Association of being overweight with greater asthma symptoms in inner city black and Hispanic children. J Pediatr 1998; 132:699-703

22 Gennuso J, Epstein LH, Paluch RA, et al. The relationship between asthma and obesity in urban minority children and adolescents. Arch Pediatr Adolesc Med 1998;152:1 197-200.

23 Redd SC, Mokdad AH. Invited commentary: obesity and asthma - new perspective, research needs, and implications for control programs. Am J Epidemiol 2002; 155:198-9.
24 Stenius-Aarniala B, Poussa T, Kvarnström J, et al. Immediate and long term effects of weight reduction in obese people with asthma: randomised controlled study. $B M$ 2000;320:827-32.

25 Jarvis D, Chinn S, Potts J, et al. Association of body mass index with respiratory symptoms and atopy: results from the European Community Respiratory Health Survey. Clin Exp Allergy 2002;32:831-7.

26 Altman DG, Bland JM. Interaction revisited: the difference between two estimates. BM 2003;326:219.

27 Chen Y, Dales R, Krewski D, et al. Increased effects of smoking and obesity on asthma among female Canadians: the national population health survey, 1994-1995. Am J Epidemiol 1999; 150:255-62.

28 Camargo CA Jr, Weiss ST, Zhang S, et al. Prospective study of body mass index, weight change, and risk of adult-onset asthma in women. Arch Intern Med 1999;159:2513-4.

29 Huang S-L, Shiao G. - M, Chou P. Association between body mass index and allergy in teenage girls in Taiwan. Clin Exp Allergy 1999;29:323-9.

30 Xu B, Järvelin M. -R, Pekkanen J. Body build and atopy. J Allergy Clin Immunol 2000;105:393-4.

\section{Air pollution and lung cancer: what more do we need to know?}

\section{A J Cohen}

\section{Further work is needed to quantify the effect of outdoor air pollution on lung cancer}

L ung cancer accounts for 1.2 million deaths yearly worldwide, exceeding -mortality from any other cancer in the developed countries. ${ }^{1}$ The vast majority are caused by tobacco smoking, but environmental causes of cancer, including air pollution, have long been a concern also. ${ }^{2}$ Outdoor air pollution has received particular attention lately as research has proliferated linking exposure, even at low ambient levels, to a wide range of adverse health effects including increased mortality and morbidity from non-malignant cardiovascular and respiratory disease and lung cancer. In response, international agencies such as the World Health Organization and governments in Europe, the US and Canada have reviewed existing air quality standards and, in many cases, moved to strengthen them. In the developed countries, where air quality has generally improved in recent decades, the scientific basis and public health efficacy of these actions have been questioned by industries whose emissions are regulated and others. In this context, reports linking air pollution and lung cancer are likely to attract attention and generate controversy. The publication of the paper by Nafstad and colleagues in this issue of Thorax is an occasion to consider both the contribution of this study to the evidence linking air pollution and lung cancer and what additional research may be needed. ${ }^{3}$

Exposure to outdoor air pollution has been associated with small relative increases in lung cancer in studies conducted over the past four decades. ${ }^{4}$ The epidemic of lung cancer emerging in the 1950s in the US and Europe motivated early research on the role of air pollution, including studies of migrants and urban-rural comparisons but, as the role of cigarette smoking became increasingly clear, interest in air pollution waned. However, recent prospective cohort and case-control studies which have taken into account tobacco smoking, as well as occupational and other risk factors, have continued to report increases in lung cancer associated with air pollution. ${ }^{5-7}$ The American Cancer Society (ACS) study, which included 10749 lung cancer deaths, reported that each $10 \mu \mathrm{g} / \mathrm{m}^{3}$ increment of fine particles $\left(\mathrm{PM}_{2.5}\right)$ was associated with an $8-14 \%$ increase in lung cancer. ${ }^{7}$ A causal interpretation is buttressed by other evidence. Urban air contains known and suspected human carcinogens such as benzo $[\alpha]$ pyrene, benzene, and 1,3-butadiene, together with carbon based particles onto which carcinogens may be adsorbed, oxidants such as ozone and nitrogen dioxide, and oxides of sulphur and nitrogen in particle form. Increased lung cancer has also been reported among workers occupationally exposed to components of urban air pollution such as polycyclic aromatic hydrocarbons and diesel exhaust. $^{89}$

In light of this evidence, the question is arguably not "Does air pollution cause some lung cancers?", but rather "How many excess cases is it likely to cause?". The answer to this question, and another-"Which pollutants, emitted by which sources, may be responsible?"-can potentially inform regulatory action to improve air quality and public health.

The current evidence suggests that lung cancer attributable to air pollution may occur among both smokers and non-smokers, and therefore both residual confounding and effect modification of the air pollution relative risk due to cigarette smoking must be considered. Nafstad et $a l^{3}$ report the relative risks of air pollution adjusted for cigarette smoking, but adjustment may not have controlled completely for potential confounding. The authors acknowledge that their study, like most other cohort studies, has information on cigarette 
smoking only at the beginning of the follow up period. The possibility that changes in tobacco use are correlated with exposure is difficult to rule out, although the association of lung cancer with air pollution was largely unaffected in the Six Cities study ${ }^{5}$ when longitudinal information on cigarette smoking was used in a recent reanalysis, ${ }^{10}$ and several case-control studies have found an increased risk following adjustment using time varying information. ${ }^{6}$ Several studies, including the one reported here by Nafstad et al, show an increased risk of lung cancer among self-reported never smokers, but the numbers in any single study are very small and the estimates imprecise. This also complicates efforts to estimate the numbers of cases in which both air pollution and smoking play a role. A study that includes large numbers of well documented never smokers may be the only approach that could address these concerns, if feasible.

Past approaches to exposure measurement also contribute to uncertainty in risk estimates. The ACS and Six Cities studies estimated the exposure of each participant based solely on long term average concentrations in their metropolitan area of residence. This approach may accurately reflect exposure to pollutants distributed homogenously over large areas for several decades but, if exposure at finer spatial and temporal scales is important, the estimates of relative risk may be inaccurate. Newer European and North American studies have begun to use spatial statistical methods to estimate individual long term exposure histories, linking residential histories, measurements of traffic density on nearby streets, and long term records of specific air pollutants, and can estimate how the size of the relative risk varies in time and space. ${ }^{611}{ }^{12}$ Hoek et al $^{11}$ observed larger relative effects on mortality from cardiopulmonary diseases as a result of air pollution near to major roads than from larger scale urban and regional air pollution, and Nyberg et $a l^{6}$ estimated the highest relative risks of lung cancer for exposure 20 years or more before diagnosis. By providing exposure estimates at the individual level, these studies also reduce the possibility of aggregate level (ecological) bias. ${ }^{1013}$

The effect of air pollution on lung cancer, fully manifest only decades after exposure, is a moving target. The emergence of cars and trucks as dominant modes of transportation and the decline in heavy industrial manufacturing in some developed countries since the mid 20th century, combined with effective air quality regulations, have changed both the nature of urban air pollution and patterns of human exposure. Over the time course of many recent lung cancer studies, decreases in larger respirable and fine particles as well as some gaseous pollutants and carcinogens have been documented, ${ }^{7}$ although concentrations of the fine, and arguably more toxic, particles may have declined to a lesser extent than other pollutants, increased in some locations, ${ }^{14}$ or changed their spatial distributions. Epidemiologists must rely on whatever components of the air pollution mix have been measured over extended periods, and consequently have reported associations of lung cancer with long term exposure to particles, ozone, sulphur dioxide, and nitrogen dioxide, but not known carcinogens. No mechanisms by which these pollutants per se cause cancer have been identified, and although some cancer biomarkers have been associated with air pollution exposure in non-smokers, they have not been used in large studies designed to estimate lung cancer risk. Nafstad et $\mathrm{al}^{3}$ and Nyberg et $a l^{6}$ used ambient concentrations of nitrogen dioxide and sulphur dioxide as surrogates for air pollution from mobile sources and residential heating, respectively. Each observed an increased risk of lung cancer associated with the nitrogen dioxide based indicator but not with the sulphur dioxide based indicator, but neither of these pollutants is specific to either source. As technological improvements and regulatory efforts continue to change the nature of air pollution, estimating current and future impacts on lung cancer will remain a challenge.

Exposure to air pollution is estimated to contribute to 62000 lung cancer deaths per year worldwide-a large number of deaths, to be sure, but considerably less than the 712000 deaths from non-malignant cardiac and respiratory disease attributable to air pollution. ${ }^{15}$ These impacts are largely borne by the populations of highly polluted cities in developing countries-roughly $60 \%$ of the world's burden of air pollution attributed disease. In Chinese cities, where air pollution levels are many times greater than those in the cities of the developed West, outdoor air pollution may contribute to as much as $10 \%$ of lung cancer overall, and perhaps a larger proportion in nonsmoking women. Unfortunately, because there is a lack of suitable studies in developing countries, these estimates are based on extrapolating the relative risk estimates from the ACS study to China, India, and other settings where differences in health status and the air pollution mixture introduce large uncertainties.

Opportunities to strengthen the scientific evidence on air pollution and lung cancer should be pursued, including in developing countries where the estimated health impact of air pollution and the need for accurate risk estimates are greatest. Studies should be designed to address, in addition to lung cancer, other arguably more important knowledge gaps such as the effect of long term exposure on the incidence of chronic non-malignant cardiorespiratory disease. Beginning large studies de novo would entail major financial and opportunity costs, so identifying existing cohorts, especially those with large numbers of non-smokers and for whom biological samples have been stored, may be the best option. Studies of outdoor air pollution and lung cancer in developing countries will need to account for past or concurrent exposures to indoor air pollution, particularly from use of coal for cooking and heating, a major cause of lung cancer in poor rural women in China and elsewhere, ${ }^{16}$ and changing patterns of tobacco smoking.

Thorax 2003;58:1010-1012

\section{Author's affiliation}

A J Cohen, Health Effects Institute, Charlestown Navy Yard, 120 Second Avenue, Boston, MA 02129, USA;

acohen@healtheffects.org

The views expressed in this paper are those of the author and do not necessarily reflect the views of the Health Effects Institute (HEI) or its sponsors.

\section{REFERENCES}

1 World Health Organization. The World Health Report 2002: reducing risks, promoting healthy life Geneva: World Health Organization, 2002

2 Epstein SS, Swartz J. Fallacies of lifestyle cancer theories. Nature 1981;289:127-30.

3 Nafstad P, Håheim LL, Oftedal B, et al. Lung cancer and air pollution: a 27 -year follow up of 16209 Norwegian men. Thorax 2003;58:1071-6.

4 Samet JM, Cohen AJ. Air pollution and lung cancer. In: Holgate ST, Samet JM, Koren HS, Maynard R, eds. Air pollution and health. london: Academic Press, 1999:841-64.

5 Dockery DW, Pope AC, Xu X, et al. An association between air pollution and mortality in six US cities. N Engl J Med 1993:329:1753-9.

6 Nyberg FP, Gustavsson L, Jarup T, et al. Urban air pollution and lung cancer in Stockholm. Epidemiology 2000; 1 1:487-95.

7 Pope CA III, Burnett RT, Thun MJ, et al. Lung cancer, cardiopulmonary mortality, and long term exposure to fine particulate air pollution. JAMA 2002;287:1132-41.

8 Boffetta P, Jourenkova N, Gustavsson P. Cancer risk from occupational and environmental exposure to polycyclic aromatic hydrocarbons. Cancer Causes and Control 1997;8:444-72.

9 Lipsett M, Campleman S. Occupational exposure to diesel exhaust and lung cancer: a meta-analysis. Am J Public Health 1999:89: 1009-17.

10 Health Effects Institute (HEI). Reanalysis of the Harvard Six Cities Study and the American Cancer Society study of particulate air pollution and mortality, A Special Report of the Institute's 
Particle Epidemiology Reanalysis Project. Cambridge, MA: Health Effects Institute, 2000.

11 Hoek GB, Brunekreef S, Goldbohm P, et al. Association between mortality and indicators of traffic-related air pollution in the Netherlands: a cohort study. Lancet 2002;360:1203-9.

12 Reynolds P, Elkin E, Scalf R, et al. Case-control pilot study of traffic exposures and early childhood leukemia using a geographic information system. Bioelectromagnetics 2001;5:S58-68.
13 Anon. Exposure assessment in studies on the chronic effects of long-term exposure to air pollution, Report on a WHO/HEl Workshop, Bonn, Germany, 4-5 February 2002. Copenhagen: World Health Organization Regional Office for Europe, 2003.

14 Cass GR, Conklin MH, Shah JJ, et al. Elemental carbon concentrations: estimation of an historical data base. Atmos Environ 1984; 18:153-62
15 Cohen AJ, Anderson HR, Ostro B, et al. Mortality impacts of urban air pollution. In: Ezzati $M$, Lopez AD, Rodgers A, Murray CJL, eds. Comparative quantification of health risks: global and regional burden of disease attributable to selected major risk factors. Geneva: World Health Organization, 2003; (in press).

16 Smith KR, Mehta S. The burden of disease from indoor air pollution in developing countries: comparison of estimates. Int $J$ Hygiene Environ Health 2003 (in press)

\section{Hypothesis: Ill health associated with low concentrations of nitrogen dioxide-an effect of ultrafine particles?}

\section{A Seaton, M Dennekamp}

\section{The epidemiological associations between illness and nitrogen dioxide may be the consequence of confounding by particle numbers}

n 1996 the Expert Panel on Air Quality Standards (EPAQS) recommended an ambient air standard for nitrogen dioxide $\left(\mathrm{NO}_{2}\right)$ in the UK of $150 \mathrm{ppb}$ measured hourly. ${ }^{1}$ This recommendation, like those for carbon monoxide ( $\mathrm{CO})$ and sulphur dioxide $\left(\mathrm{SO}_{2}\right)$ that had preceded it, was based on human toxicology rather than on epidemiology. The EPAQS was unable to find evidence that these gases were likely to be toxic to humans at the recommended concentrations. However, at the time of the $\mathrm{NO}_{2}$ recommendation there was already epidemiological evidence that effects on populations rather than individuals might be associated with much lower concentrations and the EPAQS recommended that steps be taken to reduce annual average concentrations, although without proposing a long term standard. The UK government has subsequently adopted, as targets to be achieved by 2005, World Health Organization $\mathrm{NO}_{2}$ guideline standards of $105 \mathrm{ppb}\left(200 \mu \mathrm{g} / \mathrm{m}^{3}\right)$ over 1 hour and $21 \mathrm{ppb}\left(40 \mu \mathrm{g} / \mathrm{m}^{3}\right)$ as an annual average, the latter having been based on possible relationships between exposure to the gas and respiratory illness in children. ${ }^{2}$ Achievement of a long term standard does, of course, have the desirable consequence of reducing peaks and therefore short term exceedences.
However, compliance with a very low average concentration of $\mathrm{NO}_{2}$ implies a substantial reduction in the concentration of the primary pollutant released from vehicle exhausts-that is, nitric oxide (NO). Since NO reacts with ozone to form $\mathrm{NO}_{2}$, lower concentrations will result in raised urban ozone concentrations, a gas that also has known toxic effects on the lungs and that, until now, has been seen primarily as a rural pollutant in the UK.

Progressive reductions in pollution are welcomed by many because of a belief that human health and the ecology of the planet will benefit, but it must be remembered that they are attained at a cost to industry and thus to society. That cost may be offset by reductions in health expenditure, by increases in life expectancy and crop productivity, and by opportunities for the innovative in designing more efficient engines and fuels. The components of this equation can at present only be estimated very uncertainly, therefore setting tight standards tends to be an act of faith, typically driven by political balancing of the exhortations of pressure groups on both sides. This makes it particularly important to attempt to quantify the health effects of pollutants, a process that has traditionally been based on known toxicological effects but now increasingly relies on epidemiological relationships.

\section{TOXIC EFFECTS OF NITROGEN DIOXIDE: EPIDEMIOLOGY OR TOXICOLOGY?}

Scientific confusion arises from the different viewpoints of toxicologists and epidemiologists which may be illustrated by considering $\mathrm{NO}_{2}$. Human inhalation challenge studies have shown that normal healthy individuals do not show adverse effects to $\mathrm{NO}_{2}$ below concentrations of about $2000 \mathrm{ppb}$ (about $4000 \mu \mathrm{g} / \mathrm{m}^{3}$ ). Asthmatic subjects may react to concentrations as low as $250 \mathrm{ppb}$ (about $500 \mu \mathrm{g} / \mathrm{m}^{3}$ ), either by alterations in bronchial reactivity or by increased sensitivity to inhaled allergens. Such subclinical changes might reasonably be expected to be associated with occasional exacerbations of asthma in very susceptible individuals in an exposed population. However, it is difficult to imagine that concentrations less than half of this could be responsible for clinically measurable episodes of illness, or that concentrations around a fifth of this could cause chronic health problems. While epidemiological studies have sometimes been able to detect associations that suggest health benefits may accrue by adhering to standards set at such very low concentrations, the overall message from these studies is confusing. For example, the WHO review in $2000^{3}$ concluded that "the most consistent general impression is of increased respiratory illness in older children". The report goes on to speculate that such episodes may set the scene for chronic lung disease in later life. This conclusion was weighted by consideration of studies of children living in houses with and without gas cookers. However, such studies have shown equivocal results, one metaanalysis having shown a significant effect $^{4}$ and another not. ${ }^{5} 6$ As we have shown, gas cooking may entail very high acute exposures to both $\mathrm{NO}_{2}$ and particles. $^{7}$ In fact, the heterogeneity of epidemiological findings with respect to $\mathrm{NO}_{2}$ led the UK Department of 
Health's Committee on the Medical Effects of Air Pollutants to conclude in 1998 that this pollutant should not be included in its quantitative estimates of the effects of pollutants on health. ${ }^{8}$ It is plain that the evidence on which the long term $\mathrm{NO}_{2}$ standard is based is insecure.

Epidemiological studies usually rely on the assumption that the exposures of all individuals in the population may be taken as those measured by one or a few city centre monitors. This method has the incidental effect of obscuring any threshold that may be present, ${ }^{9}$ leading to the possibly erroneous conclusion that there is no absolutely safe level of the gas in population terms. The epidemiologist may argue, with justification, that the toxicologist can only study relatively small numbers of subjects who are well enough to take part, and thus cannot comment on effects on the very vulnerable who comprise a small but critical proportion of any population studied. Faced with such conflicting evidence, what action should governments take?

\section{CONFOUNDING AND EFFECT MODIFICATION}

There are many problems in interpreting epidemiological studies of air pollution, but perhaps the most important are confounding and effect modification. There are relatively few important sources of pollution in cities-vehicles, industrial and domestic combustion processes outdoors, and cooking and smoking indoors. All produce a mixture of pollutants including particles, NO (oxidised by atmospheric ozone to $\mathrm{NO}_{2}$ ), and CO. Particles, with which adverse health effects have been associated most consistently, are usually measured as $\mathrm{PM}_{10}$ (the mass of those that are less than $10 \mu \mathrm{m}$ in aerodynamic diameter), a metric that includes a varying contribution from non-combustion sources. There are plausible hypotheses to explain the association of exposure to low concentrations of particles with both respiratory and cardiovascular illness and death ${ }^{10-12}$; this cannot be said of any associations between $\mathrm{NO}_{2}$ and such illnesses.

It is apparent that, in urban pollution episodes, particles and $\mathrm{NO}_{2}$ rise and fall together, making it difficult or impossible to separate their effects. Some studies have been particularly interesting in this regard. One observed an association between the triggering of implanted defibrillators and ambient concentrations of both particles and $\mathrm{NO}_{2}$, the latter effect appearing to be somewhat stronger. ${ }^{13}$ If $\mathrm{NO}_{2}$ was indeed responsible, individuals with such devices would be well advised to avoid entering kitchens containing gas cookers where $\mathrm{NO}_{2}$ concentrations may rise to $1000 \mathrm{ppb}$ (approximately $2000 \mu \mathrm{g}$ / $\left.\mathrm{m}^{3}\right){ }^{7}$ Another study in eight European cities showed that the association between particle concentrations (as $\left.\mathrm{PM}_{10}\right)$ and acute cardiac episodes was eliminated by controlling for $\mathrm{NO}_{2}$, strongly suggesting confounding. ${ }^{14}$ Effect modification is suggested by a study in which greater effects of $\mathrm{NO}_{2}$ on mortality occurred in cities with higher $\mathrm{PM}_{10}$ concentrations, ${ }^{15}$ and by another that has shown a stronger effect of particles (measured as black smoke, a metric roughly equivalent to $\mathrm{PM}_{4.5}$ ) on respiratory admissions when $\mathrm{NO}_{2}$ concentrations were simultaneously raised. ${ }^{16}$

This issue of confounding and/or effect modification is important. If a demonstrated association is a consequence of confounding by some other toxic substance, the effect of one may be ignored in terms of standard setting, whereas if the association is explained by effect modification, both toxic substances require regulation. Of course, if both come from a common source, regulation of one may regulate the other, but this cannot be guaranteed as changes in technology may increase one by reducing the other. Is it conceivable that these confusing associations are the consequence of confounding of all the above mentioned apparently toxic substances by one as yet unmeasured substance? We think that they may be, the confounder being the number of particles and thus the surface area presented to the lung.

\section{PARTICLE NUMBERS AND NITROGEN DIOXIDE}

The particulate aerosol we inhale comprises particles of all sizes ranging from organic matter like pollen grains some $10 \mu \mathrm{m}$ or more in diameter to primary combustion particles of $10 \mathrm{~nm}$ diameter. The smallest tend to aggregate rapidly into what are still submicron particles.
When we measure particles as massfor example, $\mathrm{PM}_{10}, \mathrm{PM}_{2.5}$ or black smoke-the greatest contribution comes from the largest particles, but the greatest number of particles by far are the submicron ones. These ultrafine particles are generated, as is NO, by the combustion process, and therefore the two pollutants (and $\mathrm{NO}_{2}$ ) are likely to correlate closely. We have carried out two separate investigations during which we have measured simultaneously particle number counts (by TSI 3934 scanning mobility particle sizer) and nitrogen oxides (by ML9841A chemoluminescent analyser). The first of these was in an unventilated laboratory during a study of the effects of electric and gas cooking on indoor pollution, the pollution source being a gas cooker. ${ }^{7}$ Figure 1 shows the close relationship between the two pollutants when derived from a common source. The second was a study of the effects of exposures to particles on the health of individuals with chronic lung disease over the course of 6 months, the measurements being made at a background site in Aberdeen city. Here we found a very striking association between concentrations of nitrogen oxides and the number of particles of $<100 \mathrm{~nm}$ aerodynamic diameter measured simultaneously (fig 2); this association was stronger than the corresponding associations with particles measured as mass (table 1). These associations are so close that it would be impossible to distinguish their effects in epidemiological studies. Thus, if $\mathrm{NO}_{2}$ in these environments is measured as an index of pollution and is shown to be associated with health effects, these effects could equally be due to the numbers of particles.

\section{IS PARTICLE NUMBER THE VILLAIN?}

The number of particles is an important and usually unmeasured confounder in studies in which both particle mass and $\mathrm{NO}_{2}$ are associated with health effects.

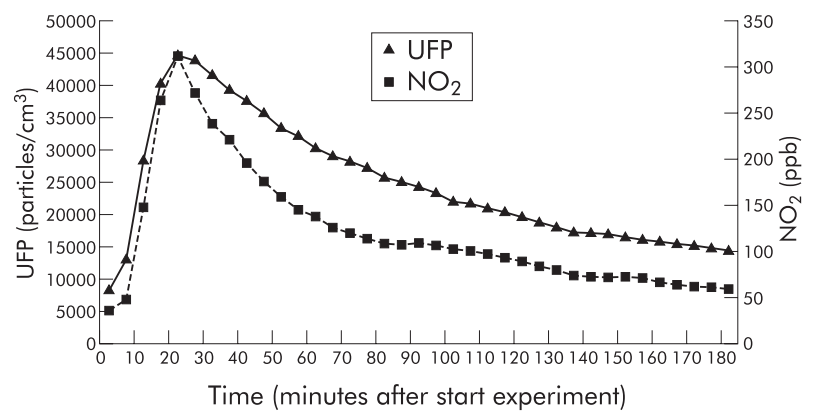

Figure 1 Indoor ultrafine particle number (UFP) and nitrogen dioxide $\left(\mathrm{NO}_{2}\right)$ concentrations in an unventilated laboratory over 3 hours during and after burning of one gas ring for 15 minutes $(r=0.97)$ 


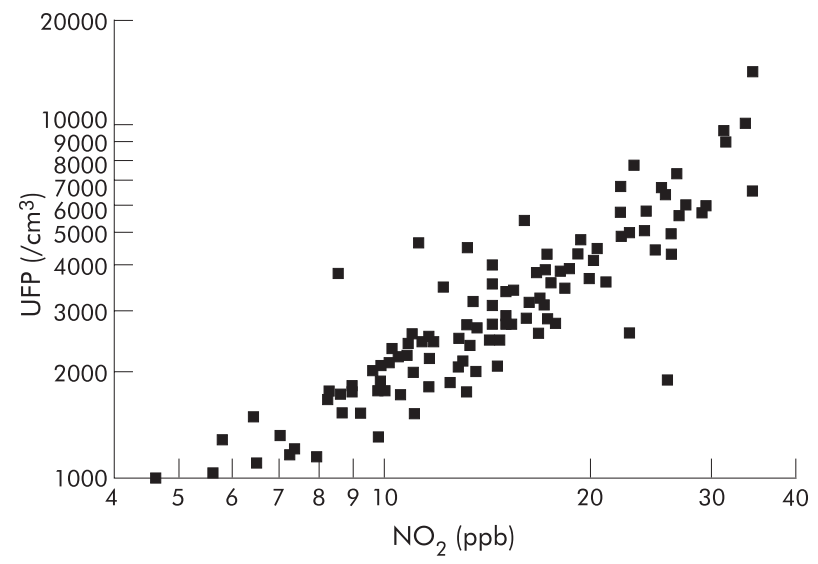

Figure 2 Relationship between mean outdoor air 24 hour counts of particles $<100 \mathrm{~nm}$ in diameter (UFP) and nitrogen dioxide $\left(\mathrm{NO}_{2}\right)$ concentrations in parts per billion. Data represent 6 months of continuous side by side measurement.

We are left to argue, from toxicological considerations, which of these is likely-at the known concentrations to which individuals are exposed-to cause the observed effects. At the moment there is evidence for toxic effects of ultrafine particles at quite low concentrations in animals. ${ }^{17}$ Relatively few studies have related particle numbers to cardiorespiratory illness, the most detailed being those of Wichmann's group in Erfurt, Germany. They have shown a somewhat weaker correlation between gases and particle numbers than us, but they have shown associations between numbers, $\mathrm{NO}_{2}, \mathrm{SO}_{2}, \mathrm{CO}$ and cardiorespiratory deaths. ${ }^{18}{ }^{19}$ It should be noted that, in contrast to most UK cities, domestic heating in Erfurt makes an important contribution to particulate pollution in the winter and $\mathrm{SO}_{2}$ concentrations are higher. Wichmann and colleagues concluded that the apparent effects of the gases were likely to be a result of confounding.

\section{PARTICLES AS MICROBES - AN HYPOTHESIS}

A plausible explanation for this toxicity is as follows. We hypothesise that the lung reacts to particle numbers rather than mass, since its primary defensive role is to counter invasion by microorganisms which may be inhaled in large numbers but never in high mass. The first requirement of the lung is to kill organisms in situ and/or to transfer them to lymph nodes where immune responses may be concentrated, and ingestion by macrophages is central to this mechanism. Ultrafine particles, however, may evade this and pass directly through the alveolar wall, thus being able directly to influence endothelial cell structures. Both macrophages and endothelium release mediators that have local and more general influences, one of which is to signal that bloodstream invasion may be imminent; a systemic reaction-the acute phase response-is a consequence. If we assume that the lung treats small particles as microorganisms, it is reasonable to propose that its response relates to numbers rather than mass. By altering blood coagulability and possibly by destabilising atheromatous plaques, this systemic response may be responsible for the acute cardiac effects seen in vulnerable individuals. It seems far more plausible that these effects are a response to the number of particles rather than to $\mathrm{NO}_{2}$, for which no comparable hypothetical explanation of effects at such low concentrations has yet been proposed.

Table 1 Pearson correlation coefficients for the logged daily outdoor concentrations of $\mathrm{NO}_{2}, \mathrm{NO}$, particle numbers, $\mathrm{PM}_{2.5}$ and $\mathrm{PM}_{10}$ in Aberdeen

\begin{tabular}{llll}
\hline & Particle numbers & $\mathbf{P M}_{2.5}$ & $\mathbf{P M}_{10}$ \\
\hline No of particles $<200 \mathrm{~nm}$ diameter & & 0.56 & 0.40 \\
& & $(\mathrm{n}=124)$ & $(\mathrm{n}=121)$ \\
Nitric oxide $(\mathrm{NO})$ & 0.86 & 0.45 & 0.39 \\
& $(\mathrm{n}=115)$ & $(\mathrm{n}=121)$ & $(\mathrm{n}=117)$ \\
Nitrogen dioxide $\left(\mathrm{NO}_{2}\right)$ & 0.89 & 0.55 & 0.45 \\
& $(\mathrm{n}=115)$ & $(\mathrm{n}=121)$ & $(\mathrm{n}=117)$ \\
\hline
\end{tabular}

Each box gives correlation coefficient and number of daily observations. All correlations were significant at $\mathrm{p}<0.001$.

The toxicity of microorganisms does not, of course, depend entirely on the numbers inhaled; their inherent ability to initiate cell damaging reactions or to resist defences is critically important. Similarly, not all inhaled particles would be expected to be equally toxic-for example, quartz and titanium dioxide. Thus, something other than particle numbers needs to be invoked to explain their effects, and this is likely to be the nature of the surfaces they present to the lung's defences. ${ }^{12}{ }^{17} \mathrm{~A}$ further step in explaining toxicity therefore requires consideration of surface properties. However, in urban air the very smallest particles make an overwhelming contribution to the total surface area, so measurement of one represents the other.

We propose that the observed associations between ill health and $\mathrm{NO}_{2}$ at low concentrations in the ambient air are the result of confounding by particle numbers. We have earlier hypothesised that a systemic response to particle inhalation is responsible for the acute cardiorespiratory effects, ${ }^{10}$ a suggestion for which there is now considerable support..$^{20}$ This hypothesis also explains the association between air pollution and long term risk of heart disease, ${ }^{21}$ since it proposes that particles cause inflammation and thus an increase in the blood of markers such as $\mathrm{C}$ reactive protein and fibrinogen that have been associated with increased cardiac risk. Here we propose that this is a consequence of the lung's evolutionary system of defence against microorganisms. From a practical point of view, we now need to explore relations between particle numbers and illness in order to obtain evidence upon which a number standard might be considered. For the moment, however, it seems likely that in situations such as those in most UK cities where motor vehicles are the main source of pollution, measurement of $\mathrm{NO}_{2}$ is the simplest means of assessing exposures to particle numbers and, conveniently for epidemiologists, this can be done on a personal basis.

Thorax 2003;58:1012-1015

\section{Authors' affiliations}

A Seaton, M Dennekamp, Department of Environmental and Occupational Medicine, University of Aberdeen Medical School, Foresterhill, Aberdeen AB25 2ZP, UK

Correspondence to: Professor A Seaton, Department of Environmental and Occupational Medicine, University of Aberdeen Medical School, Foresterhill, Aberdeen AB25 2ZP, UK; a.seaton@abdn.ac.uk 


\section{REFERENCES}

1 Expert Panel on Air Quality Standards. Nitrogen dioxide. London: The Stationery Office, 1996.

2 World Health Organization (WHO). Guidelines for air quality. Geneva: WHO, 1999:29-31.

3 World Health Organization (WHO). Nitrogen dioxide. In: Air quality guidelines for Europe, 2nd ed. Copenhagen: WHO, 2000; chapter 7.1.

4 Hasselblad V. Synthesis of environmental evidence: nitrogen dioxide epidemiology studies. J Air Waste Manag Assoc 1992;42:662-71.

5 US Environmental Protection Agency (EPA). Air quality criteria for oxides of nitrogen. Report No EPA/600/8-91/049aF-cF.3v. Research Triangle Park, NC: US EPA, 1997.

6 Basu $R$, Samet JM. A review of the epidemiological evidence on health effects of nitrogen dioxide exposure from gas stoves. J Environ Med 1999; 1:173-87.

7 Dennekamp M, Howarth S, Dick CA, et al. Ultrafine particles and nitrogen oxides generated by gas and electric cooking. Occup Environ Med 2001;58:511-6.

8 Committee on the Medical Effects of Air Pollutants. Quantification of the effects of air pollution on health in the United Kingdom. London: The Stationery Office, 1998.
9 Watt M, Godden D, Cherrie J, et al. Individual exposure to particulate air pollution and its relevance to thresholds for health effects: a study of traffic wardens. Occup Environ Med 1995; 52:790-2

10 Seaton A, MacNee W, Donaldson K, et al. Particulate air pollution and acute health effects. Lancet 1995;345:176-8.

11 Seaton A, Soutar A, Crawford V, et al. Particulate air pollution and the blood. Thorax 1999:54:1027-32.

12 Brown DM, Wilson MR, MacNee W, et al. Size-dependent proinflammatory effects of ultrafine polystyrene particles: a role for surface area and oxidative stress in the enhanced activity of ultrafines. Toxicol Appl Pharm 2001;175:191-9.

13 Peters A, Liu E, Verrier RL, et al. Air pollution and incidence of cardiac arrhythmia. Epidemiology 2000;11:11-7.

14 Le Tertre A, Medina S, Samoli E, et al. Short-term effects of particulate air pollution on cardiovascular diseases in eight European cities. J Epidemiol Community Health 2002;56:773-9.

15 Katsouyanni K, Touloumi G, Samoli E, et al. Confounding and effect modification in the shortterm effects of ambient particles on total mortality: results within the APHEA2 project. Epidemiology $2001 ; 12: 521-31$

16 Spix C, Anderson HR, Schwartz J, et al. Shortterm effects of air pollution on hospital admissions for respiratory diseases in Europe: a quantitative summary of APHEA study results. Arch Environ Health 1998:53:54-64.

17 Donaldson K, Stone V, Seaton A, et al. Ambient particles and the cardiovascular system: potential mechanisms. Environ Health Perspect 2001;109(suppl 4):523-7.

18 Peters A, Wichmann H-E, Tuch T, et al. Respiratory effects are associated with the number of ultrafine particles. Am J Respir Crit Care Med 1997; 155:1376-83.

19 Wichmann H-E, Spix C, Tuch T, et al. Daily mortality and fine and ultrafine particles in Erfurt, Germany part I: role of particle number and particle mass. Res Rep Health Effects Inst 2000;98:5-86.

20 Schwartz J. Air pollution and blood markers of cardiovascular risk. Environ Health Perspect 2001; 109(suppl 3):405-9.

21 Hoek G, Brunekreef B, Goldbohm S, et al. Association between mortality and indicators of air pollution in the Netherlands: a cohort study. Lancet 2002;360:1203-9. the increased number of submissions means that our acceptance rate for original research papers now stands at only $12.4 \%$.

This year we have published some important original papers and useful management guidelines for common conditions including the new BTS/ SIGN (British Thoracic Society/Scottish Intercollegiate Guidelines Network) guidelines for the management of asthma in February 2003, ${ }^{67}$ BTS guidelines for the management of pulmonary embolism, ${ }^{89}$ BTS guidelines for the management of pleural disease, ${ }^{10}$ and BTS guidelines on respiratory aspects of fitness for diving. ${ }^{11}$ We have also published the Year in Review 2002, ${ }^{12}$ and have completed the review series on the pulmonary physician in critical care, ${ }^{13-17}$ continued the series on important aspects of COPD, ${ }^{18-28}$ and started a series on lung cancer. ${ }^{29-37}$

A number of new features have started in Thorax, primarily aimed at increasing the educational value of the journal. Every month we now produce our Airwaves section at the front of the journal with short paragraphs highlighting the key messages of some of whole respiratory community, owes an enormous debt of gratitude to John and Alan and the previous editorial team for their outstanding achievement.

With the advent of the new editorial team, Thorax changed to an online submission system using Bench $>$ Press. ${ }^{5}$ Although there were some initial difficulties with the change over from a paper based system to complete online submission, this is now running very well and authors, reviewers, and all our editors seem to have adapted very well to the change. The number of submissions to Thorax has increased, particularly from March 2003 , with a total of 1260 submissio 30 September 2003, representing an by a similar amount. We have also seen an increase in submissions from outside the UK, especially from North America and Canada (from 74 in 2001-2 to 126 for the past year) and a doubling in the number of submissions from Asia (table 3 ). The median time to the first decision on a paper is 38 days. However,

Figure 1 Thorax impact factor 1996-2002. 
Table 1 Submissions to Thorax by article type

\begin{tabular}{lrrrrrr}
\hline & 1998 & 1999 & 2000 & $\mathbf{2 0 0 1}$ & $\mathbf{2 0 0 2}$ & $\mathbf{2 0 0 3}$ \\
\hline Original research & & & & & & \\
$\quad$ Full papers & 398 & 453 & 505 & 573 & 592 & 860 \\
$\quad$ Short papers & 31 & 36 & 34 & 36 & 44 & N/A \\
$\quad$ Rapid communications & 7 & 3 & 6 & 9 & 6 & 0 \\
Case reports & 211 & 149 & 165 & 186 & 146 & 211 \\
Editorials/reviews & 81 & 57 & 56 & 55 & 33 & 77 \\
Review series & 13 & 19 & 14 & 15 & 40 & 26 \\
Supplement articles & 17 & 16 & 46 & 5 & 16 & N/A \\
Case report commentaries & 7 & 0 & 0 & 0 & 0 & 0 \\
Letters & 72 & 9 & 96 & 95 & 70 & 82 \\
Images in Thorax & 0 & 0 & 0 & 0 & 0 & 4 \\
Total & 837 & 812 & 922 & 974 & 947 & 1260 \\
\hline
\end{tabular}

Table 2 Thorax submissions by month, October 2002 to September 2003

\begin{tabular}{ll}
\hline October & 65 \\
November & 86 \\
December & 90 \\
January & 90 \\
February & 87 \\
March & 140 \\
April & 118 \\
May & 108 \\
June & 112 \\
July & 140 \\
August & 106 \\
September & 118 \\
\hline
\end{tabular}

the papers in the journal. We have also started the "Lung Alerts" feature as, at a time of ever increasing numbers of medical publications and a vast range of journals publishing papers of interest to practitioners in respiratory medicine, we do not have the time to scan all the general and specialist journals for papers on respiratory topics. ${ }^{38}$ A number of very important papers are published in general medical or scientific journals or in specialist journals. We have therefore started to publish short reviews and alerts of papers that we have selected from these journals. We have had an excellent response to our call to younger Thorax readers for help with this feature, and we are very grateful to all the contributors who have made this series such a success this year. In November 2003 we launched a new educational series called "Images in Thorax" in which we will publish an image or a pathological section with a short explanatory and educational note. ${ }^{39}$ The Thorax website (www.thoraxjnl.com) has proved very popular and our 10 most frequently read articles on line between December 2001 to December 2002 had a total of nearly 65000 accesses as either full text, PDF versions, or abstracts. ${ }^{40-49}$

We would like to thank all the authors who have sent us such high quality papers for review in the journal, and the many reviewers who have given up their valuable time to assess papers for Thorax and who have contributed to the success of the journal (a full list of reviewers is available on the Thorax website at www.thoraxjnl.com/supplemental). We would like to thank the Associate Editors for their invaluable help in selecting the best papers for publication and the International Advisory Board for their support of the journal. We thank Angshu Bhowmik and Terry Seemungal for organising Lung Alerts each month and Mark Fitzgerald for organising the new Images series. Ed Howard, our editorial assistant, has performed a superb job in running the journal and managing so expertly the change over to the online manuscript submission system and the office moves at the start of the year; thanks also to Julia Cresswell, our part time assistant. Finally, we would like to thank Sue King, the managing editor, for all her support in our first year and Liz Stockman, the technical editor, for ensuring that the monthly issues of Thorax are always produced to the highest standard.

This has been the first year that Thorax has operated from its permanent home in the British Thoracic Society offices in London. As our submission and peer review system is now entirely online, there is less need for the Thorax office to follow the Editors geographically and a permanent base will allow us to employ permanent editorial staff to ensure the future continuity of the journal.

Our first year as Editors of Thorax has been busy, challenging, and exciting. We are committed to ensuring that the journal continues its success and increases its impact internationally, while at the same time maintaining its educational value for the global respiratory community.

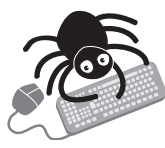

A full list of reviewers used between 1 October 2002 and 30 September 2003 is available at the Thorax website www.thoraxinl.com/supplemental.

Thorax 2003;58:1015-1017

Table 3 Geographical distribution of submissions

\begin{tabular}{lrrrrrr}
\hline & 1998 & 1999 & $\mathbf{2 0 0 0}$ & $\mathbf{2 0 0 1}$ & $\mathbf{2 0 0 2}$ & $\mathbf{2 0 0 3}$ \\
\hline UK & 265 & 326 & 348 & 323 & 325 & 378 \\
Europe excluding UK & 274 & 259 & 310 & 386 & 329 & 437 \\
USA and Canada & 76 & 81 & 87 & 68 & 74 & 126 \\
Japan & 46 & 54 & 56 & 69 & 74 & 99 \\
Australasia & 48 & 38 & 60 & 57 & 45 & 67 \\
Asia & 35 & 30 & 39 & 26 & 41 & 85 \\
South America & 3 & 1 & 5 & 7 & 6 & 21 \\
Africa & 3 & 3 & 4 & 5 & 1 & 6 \\
Middle East & 15 & 20 & 13 & 24 & 21 & 21 \\
\hline
\end{tabular}




\section{Authors' affiliations}

J A Wedzicha, S L Johnston, D M Mitchell,

Thorax Editorial Office, 17 Doughty Street, London WCIN 2PL, UK

Correspondence to: Professor J A Wedzicha i.a.wedzicha@qmul.ac.uk

\section{REFERENCES}

1 Wedzicha JA Johnston SL, Mitchell DM. New Year, new editors. Thorax 2003;58:1-2.

2 Knox AJ, Britton J. Annual report October 2000 to September 2001. Thorax 2001;56:901.

3 Knox AJ, Britton J. Journal impact factors for 2000: Thorax flying yet higher. Thorax 2001;56:587.

4 Knox AJ, Britton J. We're off: Annual report October 2001 to September 2002. Thorax 2002;57:1003-4.

5 Anon. Thorax online submission. Thorax 2002;57:1004.

6 British Thoracic Society/Scottish Intercollegiate Guidelines Network. British guideline on the management of asthma. Thorax 2003:58(Suppl I):i1-94.

7 Higgins BG, Douglas JG. The new BTS/SIGN asthma guidelines: where evidence leads the way Thorax 2003:58:98-9.

8 British Thoracic Society. British Thoracic Society guidelines for the management of suspected acute pulmonary embolism. Thorax 2003;58:470-83.

9 Miller AC, Boldy DAR. Pulmonary embolism guidelines: will they work? Thorax 2003;58:463.

10 British Thoracic Society. BTS guidelines for the management of pleural disease. Thorax 2003;58(Suppl II):ii 1-59.

11 British Thoracic Society. BTS guidelines on respiratory aspects of fitness for diving. Thorax 2003;58:3-13

12 Mitchell DM, Shaheen SO, Woodcock AA, eds. 2002 Year in Review: selected topics in respiratory medicine from 2001. Thorax 2002;57(Suppl II):ii 1-68

13 Griffiths JD, Evans TW. The pulmonary physician in critical care: towards comprehensive critical care. Thorax 2002:57:77-8.

14 Goldstone J. The pulmonary physician in critical care 10: Difficult weaning. Thorax 2002;57:986-91.

15 Davidson AC. The pulmonary physician in critical care 11: Critical care management of respiratory failure resulting from COPD. Thorax 2002;57:1079-84.

16 Phipps P, Garrard CS. The pulmonary physician in critical care 12: Acute severe asthma in the intensive care unit. Thorax 2003;58:81-8.

17 McNeil K, Dunning J, Morrell NW. The pulmonary physician in critical care 13: The pulmonary circulation and right ventricular failure in the ITU. Thorax 2003;58:157-62.

18 Lomas DA. Chronic obstructive pulmonary disease: introduction. Thorax 2002:57:735.

19 Mahadeva R, Shapiro SD. Chronic obstructive pulmonary disease 3: Experimental animal models of pulmonary emphysema. Thorax 2002:57:908-14.

20 Müller NL, Coxson H. Chronic obstructive pulmonary disease 4 : Imaging the lungs in patients with chronic obstructive pulmonary disease. Thorax 2002:57:982-5.

21 Wouters EFM. Chronic obstructive pulmonary disease 5: Systemic effects of COPD. Thorax 2002;57:1067-70.

22 White AJ, Gompertz S, Stockley RA. Chronic obstructive pulmonary disease 6: The aetiology of exacerbations of chronic obstructive pulmonary disease. Thorax 2003;58:73-80.

23 MacNee W, Calverley PMA. Chronic obstructive pulmonary disease 7: Management of COPD. Thorax 2003;58:261-5.

24 Morgan MDL, Britton JR. Chronic obstructive pulmonary disease 8: Non-pharmacological management of COPD. Thorax 2003;58:453-7.

25 Plant PK, Elliott MW. Chronic obstructive pulmonary disease 9: Management of ventilatory failure in COPD. Thorax 2003:58:537-42.

26 Meyers BF, Patterson GA. Chronic obstructive pulmonary disease 10: Bullectomy, lung volume reduction surgery, and transplantation for patients with chronic obstructive pulmonary disease. Thorax 2003;58:634-8.

27 Johnson AOC. Chronic obstructive pulmonary disease 11: Fitness to fly with COPD. Thorax 2003:58:729-32.

28 Barnes PJ. Chronic obstructive pulmonary disease 12: New treatments for COPD. Thorax 2003;58:803-8.

29 Sethi T. Lung cancer Introduction. Thorax 2002;57:992-3

30 Goodman GE. Lung cancer 1: Prevention of lung cancer. Thorax 2002;57:994-9.

31 Mulshine JL, Smith RA. Lung cancer 2: Screening and early diagnosis of lung cancer. Thorax 2002; 57: 1071-8

32 Baneriee AK, Rabbitts PH, George J. Lung cance 3: Fluorescence bronchoscopy: clinical dilemmas and research opportunities. Thorax 2003;58:266-71.

33 Cullen M. Lung cancer 4: Chemotherapy for nonsmall cell lung cancer: the end of the beginning. Thorax 2003;58:352-6.

34 Price A. Lung cancer 5: State of the art radiotherapy for lung cancer. Thorax 2003:58:447-52.

35 Sugarbaker $D$. Lung cancer 6: The case for limited surgical resection in non-small cell lung cancer. Thorax 2003;58:639-41.

36 Booton $\mathbf{R}$, Jones $M$, Thatcher $N$. Lung cancer 7 : Management of lung cancer in elderly patients. Thorax 2003;58:711-20.

37 Parker C, Neville E. Lung cancer 8: Management of malignant mesothelioma. Thorax 2003:58:809-13

38 Wedzicha JA, Bhowmik A, Seemungal T. Call for Lung Alerts. Thorax 2003;58:193.

39 Fitzgerald $M$, Muller N, Hogg J. Images in Thorax. Thorax 2003:58:915.

40 British Thoracic Society. BTS guidelines for the management of community acquired pneumonia in adults. Thorax 2001;56(Suppl IV):iv1-64.

41 British Thoracic Society. Non-invasive ventilation in acute respiratory failure. Thorax 2002;57:192-211.

42 British Thoracic Society. The British guidelines on asthma management: 1995 review and position statement. Thorax 1997;52(suppl 1):S1-21.

43 West R, McNeill A, Raw M. Smoking cessation guidelines for health professionals: an update. Thorax 2000;55:987-99.

44 Atabai K, Matthay MA. The pulmonary physician in critical care 5: Acute lung injury and the acute respiratory distress syndrome: definitions and epidemiology. Thorax 2002:57:452-8.

45 Ewig S, Baver T, Torres A. The pulmonary physician in critical care 4: Nosocomial pneumonia. Thorax 2002;57:366-71.

46 British Thoracic Society. Managing passengers with respiratory disease planning air travel: British Thoracic Society recommendations. Thorax 2002;57:289-304.

47 Baudouin SV. The pulmonary physician in critical care 3: Critical care management of community acquired pneumonia. Thorax community acquir

48 Bellingan GJ. The pulmonary physician in critical care 6: The pathogenesis of ALI/ARDS. Thorax 2002;57:540-6.

49 Leach RM, Treacher DF. The pulmonary physician in critical care 2: Oxygen delivery and consumption in the critically ill. Thorax 2002;57:170-7. 